10 Han J, Millet D, Chizzonitti B, Moe GK. Temporal dispersion of recovery of excitability in atrium and ventricle as a function of heart rate. Am Heart $\mathrm{J}$ 1966;71:481-7.

11 Evans TR, Curry PVL, Fitchett DH, Krikler DM. "Torsade de pointes" initiated by electrical ventricular stimulation. J Electrocardiol 1976;9: 255-8.

12 Gleick J. Chaos: making a new science. New York: Viking Penguin, 1987

13 Kaplan DT, Cohen RJ Is fibrillation chaos? Circ Res 1990;67:886-92.

14 Winfree AT. Sudden cardiac death: a problem in topology. Sci Am 1983 248:118-31.

15 Goldberger AL. Non-linear dynamics in heart failure: implications of long wavelength cardiopulmonary oscillations. Am Heart J 1984;107:612-5.

16 Cranefield PF, Aronson RS. Cardiac arrhythmias: the role of triggered activity and other mechanisms. New York: Futura Publishing, 1988:12.

17 El-Sherif N, Bekheit SS, Henkin R. Quinidine-induced long QTU interva and torsade de pointes: role of bradycardia-dependent early afterdepolarisations. J Am Coll Cardiol 1989;14:252-7.

18 Roden DM, Hoffman BF. Action potential prolongation and induction of abnormal automaticity by low quinidine concentrations in canine Purkinje fibers. Relationship to potassium and cycle length. Circ Res 1985;56: 857-67.

19 Corabeouf E, Deroubaix E, Coulombe A. Acidosis induced abnormal repolarizations and repetitive activity in isolated dog Purkinje fibres. J Physiol (Paris) 1980;76:97-106.

20 Levine JW, Spear JF, Guanieri T, et al. Cesium chloride-induced long QT syndrome: demonstration of afterdepolarisations and triggered activity in syndrome: demonstration of afterde
vivo. Circulation 1985;72:1092-103.

21 Tzivoni D, Keren A, Cohen AM, et al. Magnesium therapy for torsade de pointes. Am J Cardiol 1984;53:528-30.

22 Zwillinger L. Ueber die Magnesiumwirkung auf das Herz. Klin Wochenschr 1935;14:1429-33

23 Khan MM, Logan KR, McComb JM, Adgey AAJ. Management of recurrent ventricular tachyarrhythmias associated with QT prolongation. Am J Cardiol 1981;47:1301-8.

24 Bronsky D, Dubin A, Kushner DS, et al. Calcium and the electrocardiogram III. The relationship of the intervals of the electrocardiogram to the levels of serum calcium. Am J Cardiol 1961;7:840-3.

25 Brachmann J, Scherlag BJ, Rosenshtraukh LV, Lazzara R. Bradycardiadependent triggered activity: relevance to drug-induced multiform ventricular tachycardia. Circulation 1983;68:846-56.

26 Hanich RF, Levine JH, Spera JF, Moore EN. Autonomic modulation of ventricular arrhythmia in cesium-chloride-induced long QT syndrome. Circulation 1988;77:1149-61.

27 Cranefield PF. Action potentials, after potentials and arrhythmias. Circ Res 1977;41:415-23.

28 Weintraub RG, Gow RM, Wilkinson JL. The congenital long QT syndromes in childhood. J Am Coll Cardiol 1990;16:674-80.

29 Schoenenberger RA, Haefeli WE, Weiss P, Ritz RF. Association of intravenous erythromycin and potentially fatal ventricular tachycardia with Q-T prolongation (torsade de pointes). BMJ 1990;300:1375-6.

30 Stein KM, Haronian H, Mensah GA, Acosta A, Jacobs J, Kligfield P. Ventricular tachycardia and torsade de pointes complicating pentamidine therapy of pneumocystis carinii pneumonia in the acquired immunotherapy of pneumocystis carinii pneumonia in the
deficiency syndrome. Am J Cardiol 1990;66:888-9.

31 Dessertenne F. Ordre ou chaos en électrocardiographie. Nouv Presse Méd $1973 ; 2: 1511-2$.

\title{
Is there chaos in cardiology?
}

A recent paper stated that "the health care system in the United States is in chaos." Though I am sure readers know what was meant, we have to be careful these days about the definition of chaos. Consulting a medical dictionary is unhelpful because there, chaos (Pelomyxa carolinensis) is an amoeba. ${ }^{2}$ Descriptions in Webster " ("a state of things in which chance is supreme . . . nature that is subject to no law . . . a state of utter confusion completely wanting in order, sequence, organisation or predictable operation") do not quite cover the modern, mathematical redefinition of chaos.

The new chaos is characterised by deterministic behaviour, where irregular patterns obey mathematical equations and are critically dependent on initial conditions. ${ }^{4}$ Modern chaos theory has been applied to a wide variety of biological phenomena ${ }^{5}$ and has become quite fashionable. In certain circles you are regarded as a barbarian if your conversation is not garnished with terms such as Hopf bifurcation points, Liapunov numbers, phase locking, or fractals.

Chaos theory has been used in two areas of cardiac electrophysiology: (a) the behaviour of cardiac tissue, or isolated myocytes, during repetitive stimulation and $(b)$ fibrillation and prefibrillatory states.

Chaos is irregular behaviour occurring in a nonlinear dynamic system. Cardiac cells may have several nonlinear, time-dependent variables (for instance supernormal excitability) and may exhibit irregular response patterns at a certain stimulation frequency. ${ }^{67}$ When isolated sheep Purkinje fibres exposed to a solution containing $7 \mathrm{mmol} / 1$ $\mathrm{K}^{+}$are repetitively stimulated at progressively faster rates, the so-called devil's staircase is seen, where $1: 1$ responses change into $2: 1$ and $3: 1$, with intermediate Wenckebach periodicity between the $1: 1$ and $2: 1$, and $2: 1$ and $3: 1$ responses. No irregular activity occurs. When, however, the extracellular $\mathrm{K}^{+}$concentration is lowered to $4 \mathrm{mmol} / \mathrm{l}$, and the fibres exhibit a brief period of supernormal excitability during the repolarisation phase, deterministic chaotic behaviour occurs at certain cycle lengths: either the stimulus-response pattern shows complex irregularities where no sequence is ever repeated in exactly the same way (this occurs at cycle lengths around $200 \mathrm{~ms}$ ), or at cycle lengths of $50 \mathrm{~ms}$ the relation between cycle length and action potential amplitude is chaotic. 'This example is chosen to show, on the one hand, that chaotic behaviour can indeed be induced in cardiac tissue, and that some satisfaction can be derived from the consideration that a unifying concept, chaos theory, links the stimulusresponse patterns in cardiac cells with other phenomena such as growth during embryonic development ${ }^{8}$ or the activity of phrenic nerves during mechanical ventilation of anaesthetised, paralysed cats. ${ }^{5}$ On the other hand, the conditions in which chaotic activity arises are extreme: artificial stimulation of isolated tissue at a certain $\mathrm{K}^{+}$ concentration at unphysiological frequencies.

Can chaotic behaviour be detected in "naturally" occurring rhythms? The obvious candidate for study is ventricular fibrillation, which traditionally has been called chaotic in the Webster sense. The identification of chaos in an existing rhythm is difficult. One technique is power spectrum analysis. A broad-band power spectrum is associated with chaos; however, ordinary random noise has a broad power spectrum as well. The power spectrum of electrocardiographic recordings during ventricular fibrillation is narrow ${ }^{910}$ and Kaplan and Cohen concluded from their analysis that "there is little utility in classifying fibrillation as chaotic." ${ }^{10}$ Would it be useful if fibrillation, or any other rhythm or conduction disorder, could be classified as chaotic? In this respect, the investigators in the chaotic domain are very enthusiastic: "A finding that ventricular fibrillation is chaos would suggest that there is a single mechanism at work in VF, and would provide guidance in the search for clinical precursors of VF"; ${ }^{10}$ "... such new theories may help to strengthen the ties between the basic scientist and the cardiologist by opening new research avenues which may lead to the disclosure of the fundamental mechanisms of severe cardiac arrhythmias 
and sudden death"; "T "The application of nonlinear systems theory to electrophysiology ... may have clinical implications."7 In a recent paper, describing a relation between $T$ wave alternans in dogs with acute coronary artery occlusion and subsequent fibrillation, it was claimed that "a new approach is provided for quantification of susceptibility to malignant arrhythmia" and that " $T$ wave alternans may represent a prechaotic state because bifurcate behaviour is the hallmark of chaos."11

These quotes indicate that a great deal is expected from studies applying chaos theory to cardiac rhythms: more insight into arrhythmogenic mechanisms and the identification of individuals at high risk for sudden cardiac death. It is here that I have my doubts. Certainly, new avenues should be explored, and possibly "we are sure to see dramatic advances in the field" 12 if we use nonlinear dynamics as a tool to study complex cardiac rhythms. In my view, however, cardiac arrhythmias ultimately have to be understood in terms of cardiac electrophysiology, and are due to changes in variables such as conduction velocity, excitability, automaticity, afterdepolarisations, electrotonic interactions between areas in the heart with different electrical properties, which in their turn are due to changes in properties of ionic channels, pumps, and receptors in cellular and subcellular membranes. Is my understanding that $T$ wave alternans may be a harbinger of ventricular fibrillation in acute ischaemia improved because it is a prechaotic state (presumably leading to "chaotic" fibrillation where chaos is used in the old sense and not in the modern one) or because it marks the development of post-repolarisation refractoriness which sets the stage for unidirectional block, one of the prerequisites for re-entry ${ }^{13} 14$

In my opinion our insight into arrhythmogenesis will be advanced by the application of chaos theory only if the link between "modern" chaos theory and "old fashioned" electrophysiology is established. Here, a mathematician who can model iterative non-linear systems and who understands the language of the cardiac electrophysiologist and of the practicing cardiologist may be of help.

MICHIEL J JANSE

Department of Clinical and Experimental Cardiology,

Academic Medical Centre, University of Amsterdam,

Meibergdreef 9, 1105 AZ Amsterdam Zuidoost,

The Netherlands

1 Young DA. Payment policy, quality of care and decision making with inadequate information. $J$ Am Coll Cardiol 1989;14(suppl A):3A-6A.

Dorland's illustrated medical dictionary. 25th ed. Philadelphia, London, Toronto: WB Saunders, 1979.

Webster's third international dictionary. Springfield, Illinois, MA: G and C Merriam, 1971 .

$4 \mathrm{Li}$ TY, Yorke JA. Period three implies chaos. Am Math Monthly 1975; 82:985-92,

5 Glass L, Mackey MC. From clocks to chaos. The rhythms of life. Lawrenceville NJ: Princeton University Press, 1988.

6 Chialvo DR, Michaels D, Jalife J. Supernormal excitability as a mechanism of chaotic dynamics of activation in cardiac Purkinje fibres. Circ Res 1990;66:525-45.

7 Vinet A, Chialvo DR, Jalife J. Irregular dynamics of excitation in biologic and mathematical models of cardiac cells. Ann NY Acad Sci 1990 601:281-98.

8 Pyeritz RE, Murphy EA. Genetics and congenital heart disease: perspectives and prospects. J Am Coll Cardiol 1989;13:1458-68.

9 Goldberger AL, Bhargava V, West BJ, Mandell AJ. Some observations on the question: Is ventricular fibrillation chaos? Physica D 1986;19.282-9.

10 Kaplan DT, Cohen RJ. Is fibrillation chaos? Circ Res 1990;67:886-92.

11 Nearing BD, Huang AH, Verrier RL. Dynamic tracking of cardiac vulnerability by complex demodulation of the $T$ wave. Science 1991; 252:437-40.

12 Glass L. Is cardiac chaos normal or abnormal? J Cardiovasc Electrophysiol 1990;1:481-2.

13 Downar E, Janse MJ, Durrer D. The effect of acute coronary artery occlusion on subepicardial transmembrane potentials in the intact porcine heart. on subepicardial transmem

14 Janse MJ, Wit AL. Electrophysiological mechanism of ventricular arrhythmias resulting from myocardial ischemia and infarction. Physiol Rev 1989;69:1049-69. 